\title{
Relation between Lower Ionospheric Electron Density Profiles and Cosmic Noise Absorption during Auroral Zone Disturbances
}

\author{
Shigeru MiYazaki \\ Radio Research Laboratories, Ministry of Posts and Telecommunications, \\ Nukui-Kitamachi, Koganei-shi, Tokyo, Japan
}

(Received January 9, 1975; Revised March 11, 1975)

Eight rockets among a total of twenty-one rocket experiments by the 12th, 13th and 14th Japanese Antarctic Research Expedition parties were launched during auroral disturbances at night at Syowa Station, Antarctica between 1971 and 1973. The electron density profiles in the lower ionosphere between about $50 \mathrm{~km}$ and $130 \mathrm{~km}$ under various disturbed conditions were obtained by rocketborne radio frequency probes and electrostatic probes.

The collision frequency profile is derived from the electron density profiles and cosmic noise absorption measurements. There exists a maximum absorption layer in the region between $75 \mathrm{~km}$ and $85 \mathrm{~km}$, and this location of the layer is not strongly dependent on the magnitude of the ionospheric disturbance. An increase in the electron density, especially in the $D$ and $E$ region between about $75 \mathrm{~km}$ and $110 \mathrm{~km}$ has a good correlation with cosmic noise absorption; the following empirical formulae are obtained from the observational results:

$$
\Delta n_{e}=\exp (0.205 x+4.67), \quad h_{m}=-2 x+100,
$$

where $\Delta n_{e}\left(\mathrm{~cm}^{-3}\right)$ is the maximum increment of the electron density from the quiet level, $h_{m}(\mathrm{~km})$ is the height of the maximum increment of the electron density and $x(\mathrm{~dB})$ is the cosmic noise absorption.

\section{Introduction}

There are few observations of the lower ionosphere compared with observations of the ionosphere above $100 \mathrm{~km}$ due to difficulties in measuring methods and to the complicated nature of the phenomena existing in the lower ionospheric region as well. However, the study of the lower ionosphere is important because of its relation to radio wave propagation and absorption, the ionization mechanism by the cosmic rays (WEBBER, 1962), and solar radiation including $X$ rays (Whitten and Poppoff, 1965). At high latitudes, corpuscular precipitation plays an important role in the formation of the polar ionosphere 
and auroral phenomena, and ionization by bremsstrahlung is also important during auroral disturbances (KamiYama, 1966a, 1966b, 1967a, 1967b; ReEs, 1964; ReEs et al., 1969).

In 1963, the first comprehensive conference concerning the lower ionosphere was held at the University of Illinois, and the second and third conferences were held at the same place in 1965 and 1968 (UNIVERSITy OF ILlinois, 1963, 1965, 1969). These meetings covered measurement methods of lower ionospheric parameters, observational results by ground-based and rocket-borne experiments, and meteorological and chemical factors in $D$ region aeronomy. A research meeting concerning ground-based radio wave propagation in the lower ionosphere was held at Ottawa in 1966 (BeLrose, 1967). In 1971, a COSPAR symposium on $D$ and $E$ region ion chemistry was held at the University of Illinois (American Geophysical Union, 1972).

The electron density profiles in the $D$ and $E$ region can be measured by various techniques such as a low frequency sounder (WATts, 1958; SHELlmaN, 1970; WAKAI, 1971), the cross-modulation method (Holt et al., 1962), partial reflection method (Belrose and Burke, 1964; Haug, 1966; Belrose et al., 1972), riometer observation (PARThasarathy et al., 1963; Lerfald et al., 1964), radio wave absorption measurements (ELLING, 1974), incoherent scatter radar (BANKs et al., 1974), phase measurement of VLF propagation (RINNERT, 1973), and VHF propagation (WATkIns and Essex, 1973). Also, the direct measurement of the ionosphere by using sounding rocket is a powerful method (Jespersen et al., 1964, 1966; Mechtly and Smith, 1970; SeChrist, 1970; Derblom and LAdell, 1973). The electron density profiles in the ionosphere at mid-latitudes have been investigated by several authors up to the present (Maeda, 1969, 1971; Ferraro et al., 1974; Rowe, 1974), but there is insufficient data in the high latitude region. The lower ionosphere especially at high latitudes is the most imperfectly understood region of the ionosphere even at the present time.

Upon reopening of the observations of geophysical phenomena at Syowa Station $\left(69^{\circ} 00^{\prime} \mathrm{S}, 39^{\circ} 35^{\prime} \mathrm{E}\right.$; geomagnetic lat. $69.6^{\circ} \mathrm{S}$, long. $\left.77.1^{\circ} \mathrm{E}\right)$, Antarctica by the 7 th JARE (Japanese Antarctic Research Expedition) party in 1966, a concrete plan for sounding rocket experiments was made. After the successful rocket flights of S-160JA-1 and -2 by the 11 th JARE party as preliminary experiments (HIRASAw et al., 1970), the 12th, 13th and 14th JARE parties carried out firings of a total of twenty-one rockets to observe directly various basic quantities relating to the ionosphere and auroral phenomena at Syowa Station, Antarctica in the period between 1971 and 1973. The electron density profiles in the lower ionosphere under various disturbed conditions were obtained by two S-160JA and twelve S-210JA rocket experiments. Eight of the twelve 
S-210JA rockets were launched during the night. In this paper, the general study of the relation between the electron density profile and auroral zone disturbance is described.

\section{Instruments}

Ionospheric plasma probes are classified into two categories: electrostatic and radio frequency. The well-known Langmuir probe method which has long been used to measure the electron density in plasma is a typical electrostatic probe method. The electron density is calculated from the current-voltage characteristic of a sounding electrode to which DC voltage from negative to positive is applied. Cylindrical electrodes are used in these rocket experiments.

The probe electron current in the acceleration potential region is proportional to the electron density (FIndLAY and BRACE, 1969). Thus the electron density profile can be measured continuously by using the probe biased with a constant positive potential. This probe is called the electron current probe.

Plasma shows a complex impedance to radio frequency for the interaction between plasma and the electromagnetic field and the impedance changes with frequency. The radio frequency probe method is one by which the plasma parameters are measured by the use of such a property of the plasma. Two cylindrical electrodes, transmitting and receiving, are used. Radio frequency voltage of some frequency range is applied to the transmitting electrode and the signal is received by the other electrode. The following relation holds among the upper hybrid frequency, $f_{u}$, the electron plasma frequency, $f_{p}$, and the electron cyclotron frequency, $f_{c}$ :

$$
f_{u}^{2}=f_{p}^{2}+f_{c}^{2} .
$$

Using this relation, the electron density can be calculated from the upper hybrid frequency, which is obtained from the radio frequency characteristic curve of the received signal.

The radio frequency, Langmuir, and electron current probes were installed on the rockets, S-210JA-5, $-8,-9,-10,-17$ and -18 . The radio frequency probe and electron current probe were installed on rocket S-210JA-11, and only the electron current probe was installed on rocket S-210JA-19.

There are calibration systems in the Langmuir probe circuit and in the electron current probe circuit. Electron current calibrations in both electrostatic probes can be made within every 16 seconds of flight. There is also a frequency mark circuit in the radio frequency probe circuit. The frequency can be calibrated during every measuring period. With the radio frequency probe, the error of the absolute value of electron density may be about $\pm 20 \%$ (EJIRI et al., 
1973). The error in electron density measurement by the Langmuir probe may be slightly larger than that by the radio frequency probe method. With the electron current probe, the relative variations in electron density can be measured with an accuracy of a few percent (Smith, 1966), but the error of the absolute value of the electron density may amount to \pm a few tens of percent at lower altitudes of small electron density. Here, the electron density above about $90 \mathrm{~km}$ is adopted from the results obtained by the radio frequency probe, and the electron density below that level is obtained by the normalization of the results of the electron current probe.

\section{Observational Results}

Table 1 shows the general data concerning the ionospheric sounding rocket experiments, conducted in the nighttime, and the ionospheric and other conditions. Cosmic noise absorption (CNA) was observed with the riometer at the frequency of $30 \mathrm{MHz}$. Figure 1 shows the flying directions and the landing points of the rockets. The number on the line indicates the serial number of the rocket S-210JA. Figure 2 shows the rocket trajectories.

Figures 3(a) and (b) show the electron density profiles observed with the rocket S-210JA-5. In the ascending mode, the electron density increases with a steep gradient in the altitude range to about $95 \mathrm{~km}$, then the gradient of the electron density profile becomes rather small above $95 \mathrm{~km}$ with an electron density of about $1 \times 10^{5} \mathrm{~cm}^{-3}$. In the descending mode, the gradient of the electron density changes at an altitude of about $100 \mathrm{~km}$.

The spin rate of the rocket was about $1 \mathrm{~Hz}$, and there also existed a rather large precession motion of the rocket. The length of the cylindrical electrode was about $50 \mathrm{~cm}$, and the measuring electrodes entered and left the wake region

Table 1. Ionospheric sounding rockets and ionospheric and other conditions during rocket experiments.

\begin{tabular}{|c|c|c|c|c|c|c|c|c|}
\hline Rocket & Date & $\begin{array}{c}\text { Time } \\
\left(45^{\circ} \mathrm{EMT}\right)\end{array}$ & $\begin{array}{l}\text { Max. } \\
\text { alt. } \\
(\mathrm{km})\end{array}$ & $\begin{array}{l}\text { Hor. } \\
\text { dist. } \\
(\mathrm{km})\end{array}$ & $\begin{array}{l}\text { Time of } \\
\text { flying } \\
\text { (sec) }\end{array}$ & $\begin{array}{l}\text { Geomag. } \\
H \text {-comp. } \\
\text { (gamma) }\end{array}$ & $\begin{array}{c}30 \mathrm{MHz} \\
\text { CNA } \\
\text { (dB) }\end{array}$ & Ionosphere \\
\hline S-210JA- 5 & Sept. 14, 1971 & ${ }_{0050}^{h} \mathrm{~m}$ & 114.2 & 99.7 & 316 & -150 & -0.8 & $E_{s}$ \\
\hline-8 & Aug. 11, 1972 & 0401 & 126.6 & 132.2 & 335 & -450 & -2.6 & Blackout \\
\hline-9 & May 14,1972 & 0213 & 129.3 & 117.3 & 341 & -290 & -1.3 & Blackout \\
\hline-10 & May 16,1972 & 0202 & 115.4 & 60.7 & 328 & -200 & -0.3 & Spread $F$ \\
\hline-11 & Aug. 7,1972 & 0445 & 125.8 & 135.8 & 333 & -600 & -4.8 & Blackout \\
\hline-17 & Apr. 23,1973 & 0254 & 124.5 & 110.7 & 335 & -750 & -5.0 & Blackout \\
\hline-18 & Aug. 23, 1973 & 0353 & 129.4 & 128.5 & 343 & -50 & -0.5 & Unstable $E_{s}$ \\
\hline-19 & July 15,1973 & 2209 & 130.0 & 92.0 & 342 & +50 & 0.0 & $E_{s}$ \\
\hline
\end{tabular}




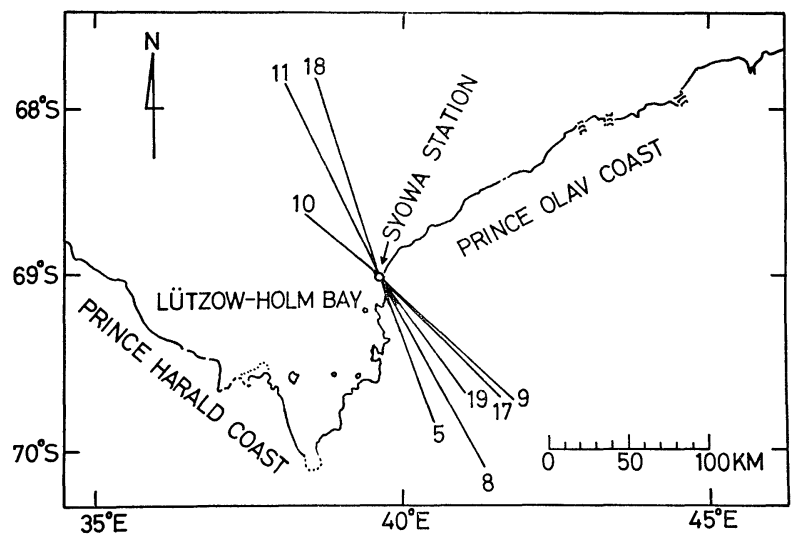

Fig. 1. Flight directions and impact points of rockets.

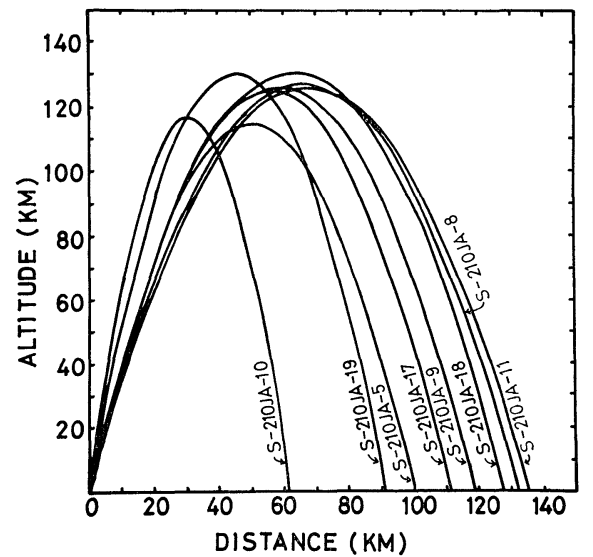

Fig. 2. Rocket trajectories.

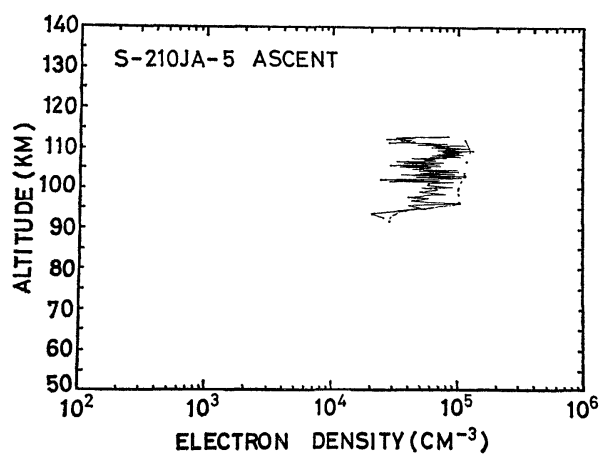

Fig. 3(a). Electron density profile at Syowa Station, Antarctica (Sept. 14, 1971;00h50m $45^{\circ} \mathrm{EMT}$ ).

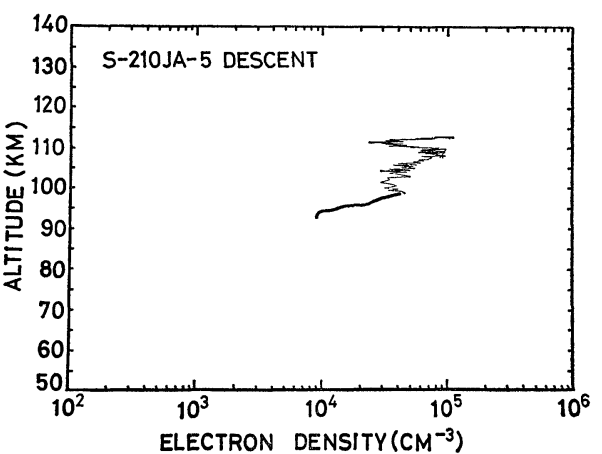

Fig. 3(b). Electron density profile at Syowa Station, Antarctica (Sept. 14, 1971;00h50m $\left.45^{\circ} \mathrm{EMT}\right)$. 


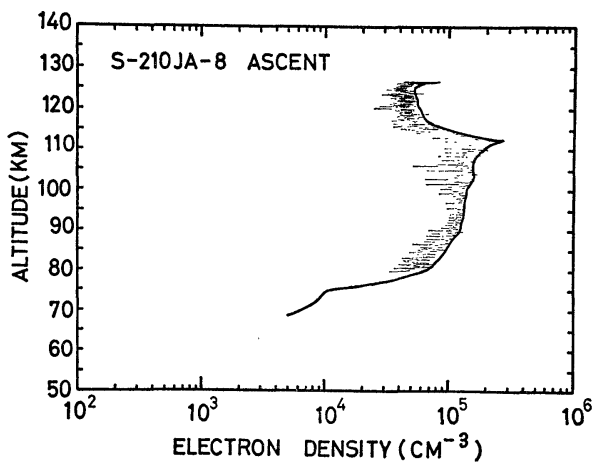

Fig. 4(a). Electron density profile at Syowa Station, Antarctica (Aug. 11, 1972; 04h01m $45^{\circ} \mathrm{EMT}$ ).

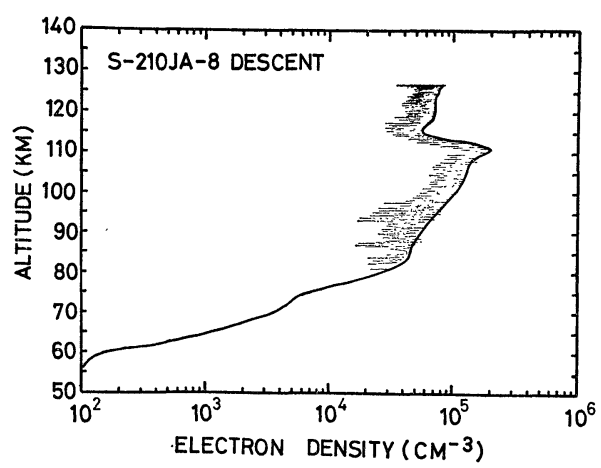

Fig. 4(b). Electron density profile at Syowa Station, Antarctica (Aug. 11, 1972; 04h01m $45^{\circ}$ EMT).

of the rocket during the spin and precession motions. The electron density in the rocket wake region was lower than that of ambient plasma. Therefore, the observed values of the electron density show increases and decreases arising from the spin and precession of the rocket. The most probable profile is derived by connecting the peak values. In Fig. 3(a), there exist three electron density maxima at the altitudes of about $97 \mathrm{~km}, 103 \mathrm{~km}$ and $110 \mathrm{~km}$. The most probable electron density profile is the dashed envelope line from the consideration of electrostatic probe measurements. In Fig. 3(b), the decrease in electron density around $112 \mathrm{~km}$ may be caused by the precession effect of the rocket.

Figures 4(a) and (b) show the electron density profiles observed with the rocket S-210JA-8 which was fired in the period of the August event, 1972 (HaKura et al., 1973; Radio Research Laboratories, 1973). The electron density increases with a steep gradient in the altitude up to about $80 \mathrm{~km}$ in both the ascending and descending modes; the gradient of the electron density profile changes at that height, and the electron density increases rather gradually up to a maximum at an altitude of about $112 \mathrm{~km}$ and then decreases with rather steep gradient above $112 \mathrm{~km}$.

Figures 5(a) and (b) show the electron density profiles observed with the rocket S-210JA-9. Although the ionogram shows that there was a radio blackout at the time of firing, it shows the occasional appearance of the $E_{s}$ layer before and after the firing time. The electron density profiles during the ascent and descent are different from each other. That is, the electron density increases monotonously to a maximum at the altitude of about $115 \mathrm{~km}$ and is about $2.5 \times 10^{5} \mathrm{~cm}^{-3}$ in the ascent. The electron density decreases above $115 \mathrm{~km}$. On the other hand, the electron density shows a maximum of about $3 \times 10^{5} \mathrm{~cm}^{-3}$ and shows a minimum at $110 \mathrm{~km}$ during descent. The difference of the electron 


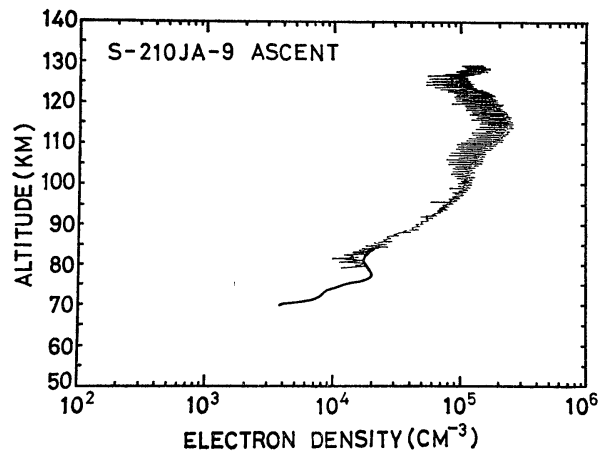

Fig. 5(a). Electron density profile at Syowa Station, Antarctica (May 14, 1972; 02h13m $\left.45^{\circ} \mathrm{EMT}\right)$.

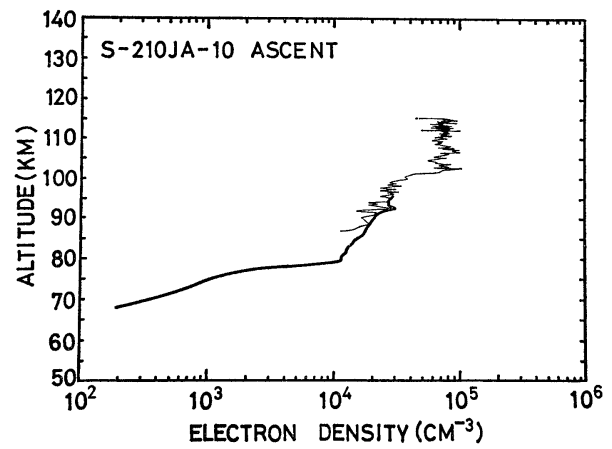

Fig. 6(a). Electron density profile at Syowa Station, Antarctica (May 16, 1972; 02h02m $\left.45^{\circ} \mathrm{EMT}\right)$.

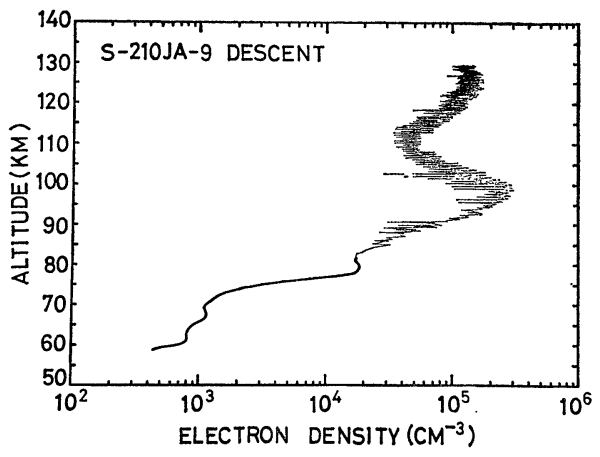

Fig. 5(b). Electron density profile at Syowa Station, Antarctica (May 14, 1972; 02h13m $\left.45^{\circ} \mathrm{EMT}\right)$.

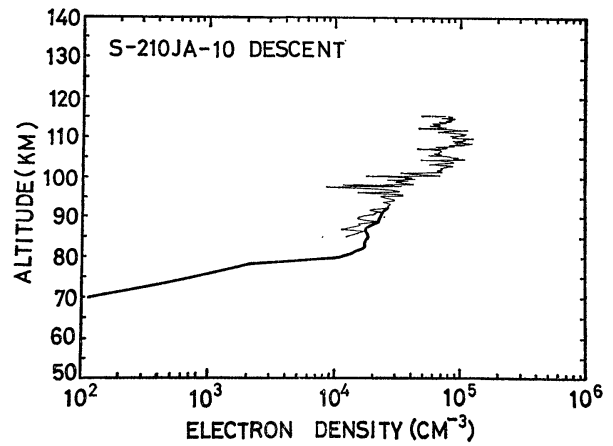

Fig. 6(b). Electron density profile at Syowa Station, Antarctica (May 16, 1972; 02h02m $\left.45^{\circ} \mathrm{EMT}\right)$.

density profiles in the ascending and descending modes is due to auroral structure. According to the all-sky photographs taken at the same time of the rocket firing, the visible aurora moved northward at first and moved southward later (OGAWA et al., 1975).

Figures 6(a) and (b) show the electron density profiles observed with the rocket S-210JA-10. At the firing time, the disturbance of the ionosphere was rather small and the ionogram shows the existence of spread $F$. The electron density increased with a steep gradient in the altitude range up to about $80 \mathrm{~km}$ and the electron density was about $8-10 \times 10^{4} \mathrm{~cm}^{-3}$ above about $100 \mathrm{~km}$ during both the ascending and descending modes.

The electron density profiles as shown in Figs. 6(a) and (b) exhibit irregular shapes. Though the reason for this is not entirely clear at the present stage, it 


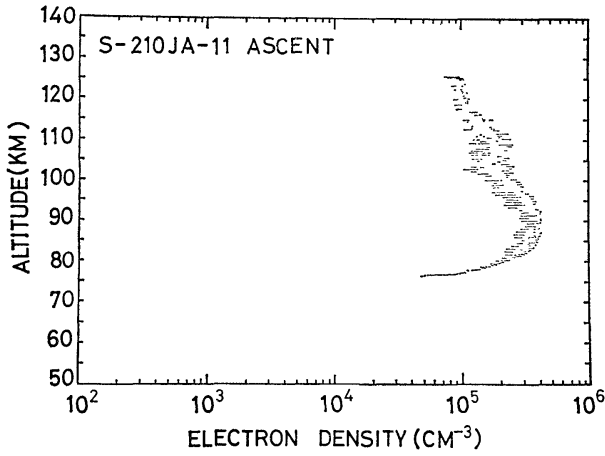

Fig. 7(a). Electron density profile at Showa Station, Antarctica (Aug. 7, 1972; 04h45m $\left.45^{\circ} \mathrm{EMT}\right)$.

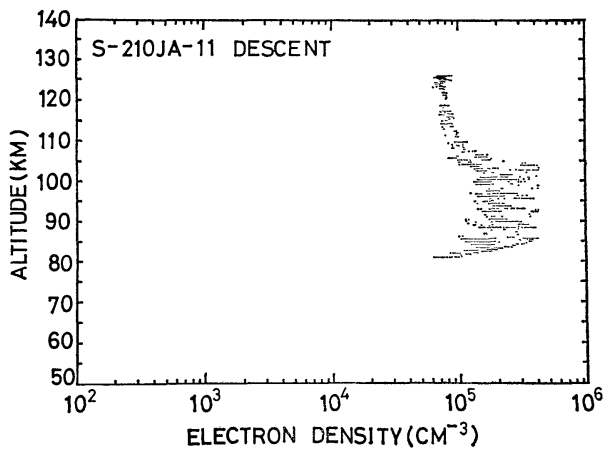

Fig. 7(b). Electron density profile at Syowa Station, Antarctica (Aug. 7, 1972; 04h45m $\left.45^{\circ} \mathrm{EMT}\right)$.

is partly caused by the wake effect due to the precession of rocket or the existence of large-scale irregularities in the ionosphere.

Figures 7(a) and (b) show the electron density profiles observed with the rocket S-210JA-11 which was fired in the period of the August event, 1972. In the ascending mode, the electron density increased with a steep gradient in the altitude range up to about $77 \mathrm{~km}$; the electron density increased gradually above $77 \mathrm{~km}$ and reached a maximum of about $4-5 \times 10^{5} \mathrm{~cm}^{-3}$ at an altitude of about $90 \mathrm{~km}$. The electron density decreased gradually above $90 \mathrm{~km}$. In the descending mode, the electron density measurements by the radio frequency probe show saturation in the altitude range between $85 \mathrm{~km}$ and $103 \mathrm{~km}$; the electron density is presumed to have a maximum of $4-5 \times 10^{5} \mathrm{~cm}^{-3}$ in that region from the electrostatic probe measurements. The electron density decreased with a steep gradient above $105 \mathrm{~km}$.

Figures $8(a)$ and (b) show the electron density profiles observed with the rocket S-210JA-17. The magnitude of the ionospheric disturbance at the firing time was the largest in these rocket experiments. Since the values obtained by the radio frequency probe in the altitude range between $90 \mathrm{~km}$ and $105 \mathrm{~km}$ in the ascent show saturation, the electron density was obtained from the measurement by the electron current probe in this region. The electron density was about 7-8 $\times 10^{5} \mathrm{~cm}^{-3}$. A maximum electron density of $6 \times 10^{5} \mathrm{~cm}^{-3}$ appeared in the region between $87 \mathrm{~km}$ and $105 \mathrm{~km}$, and the electron density decreased gradually above $105 \mathrm{~km}$ during the descent. As described before, the electron density measurements show increases and decreases due to the spin and precession of the rocket. The horizontal lines in the figures show the spread over some range of electron density from the spin effect of the rocket. The spread in the electron density is almost one order of the magnitude. The decreases in the measured 


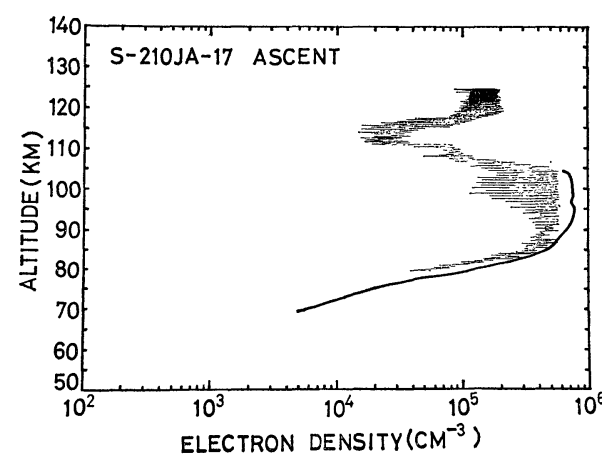

Fig. 8(a). Electron density profile at Syowa Station, Antarctica (Apr. 23, 1973; 02h54m $\left.45^{\circ} \mathrm{EMT}\right)$.

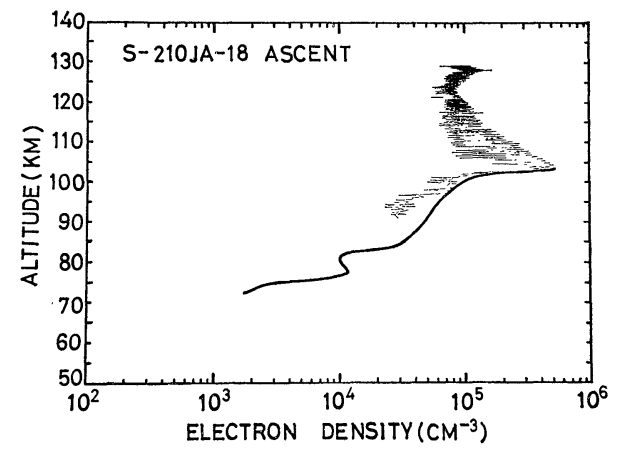

Fig. 9(a). Electron density profile at Syowa Station, Antarctica (Aug. 23, 1973; 03h53m $45^{\circ} \mathrm{EMT}$ ).

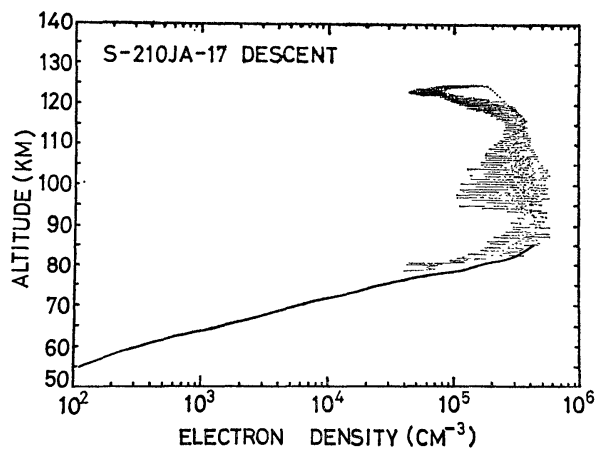

Fig. 8(b). Electron density profile at Syowa Station, Antarctica (Apr. 23, 1973; 02h54m $45^{\circ} \mathrm{EMT}$ ).

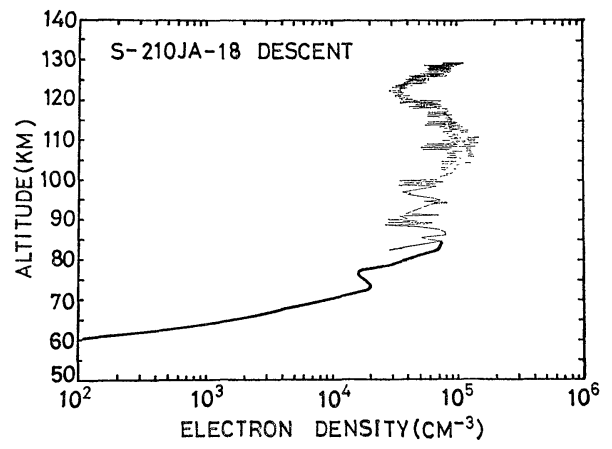

Fig. 9(b). Electron density profile at Syowa Station, Antarctica (Aug. 23, 1973; 03h53m $45^{\circ} \mathrm{EMT}$ ).

electron density in the altitude range between $105 \mathrm{~km}$ and $120 \mathrm{~km}$ in the ascent and between $121 \mathrm{~km}$ and $125 \mathrm{~km}$ in the descent are assumed to be partly caused by the rocket wake.

Figures 9(a) and (b) show the electron density profiles observed with the rocket S-210JA-18. This rocket traversed the region of visible aurora around $105 \mathrm{~km}$ in its ascent; the maximum electron density was $5.33 \times 10^{5} \mathrm{~cm}^{-3}$ at $103.4 \mathrm{~km}$. In the descending mode, there were decreases and increases in the electron density profile and the maximum electron density was about $1.5 \times 10^{5}$ $\mathrm{cm}^{-3}$. The ionosphere is assumed not to be in a severely disturbed condition.

Figures 10(a) and (b) show the electron density profiles observed with the rocket S-210JA-19. The maximum electron density was about $1 \times 10^{5} \mathrm{~cm}^{-3}$. Figure 10(a) shows the existence of the $E_{s}$ layer around $105 \mathrm{~km}$, but Fig 10 (b) shows no remarkable $E_{s}$ layer. The cause for this difference is not clear at the 


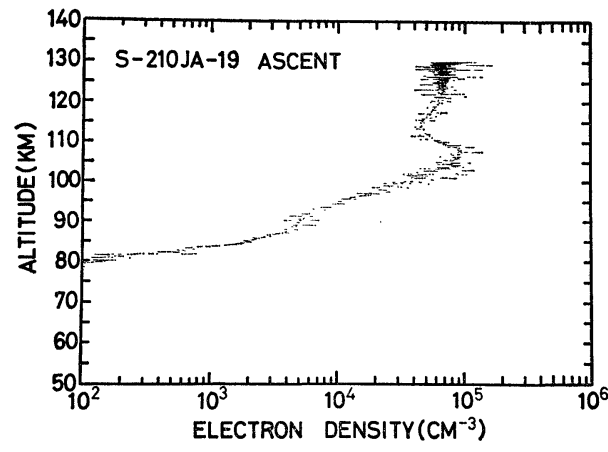

Fig. 10(a). Electron density profile at Syowa Station, Antarctica (July 15, 1973; 22h09m $\left.45^{\circ} \mathrm{EMT}\right)$.

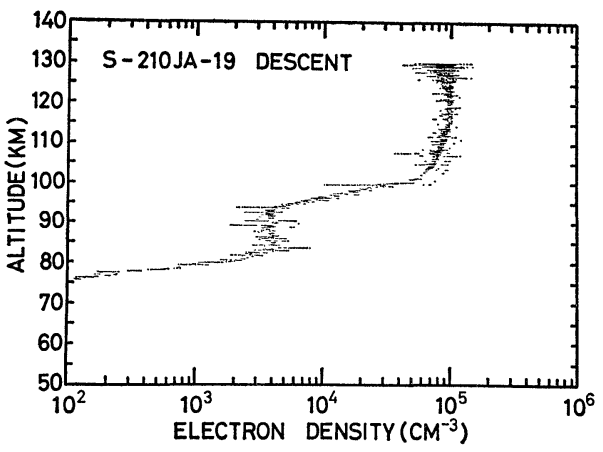

Fig. 10(b). Electron density profile at Syowa Station, Antarctica (July 15, 1973; 22h09m $\left.45^{\circ} \mathrm{EMT}\right)$.

present time. The ionosphere was rather quiet except for the appearance of the $E_{s}$ layer.

4. Relation between the Electron Density Profile and the Cosmic Noise Absorption

Figure 11 shows the electron density profiles in the ascending mode when the aurora appears in the nighttime. The author wishes to make clear in the following that the increase in the electron density, especially in the $D$ and $E$ region between about $75 \mathrm{~km}$ and $110 \mathrm{~km}$, in proportional to the magnitude of the disturbance such as the variation of the geomagnetic field and cosmic noise absorption.

The collision frequency profile is derived from the electron density profile,

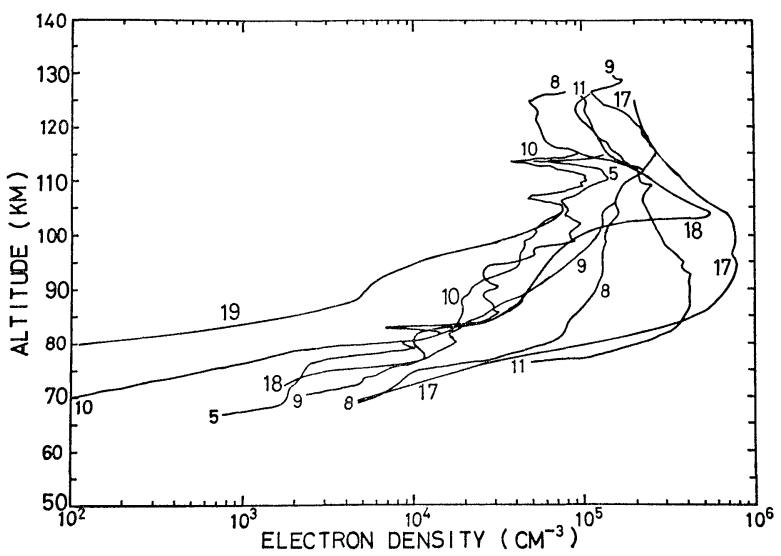

Fig. 11. Electron density profiles during auroral disturbances. 


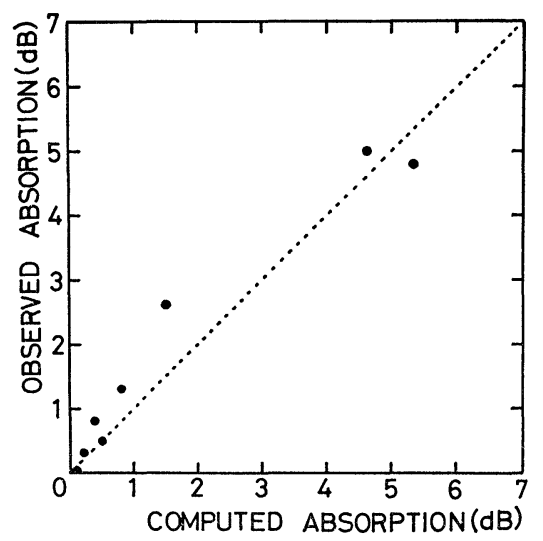

Fig. 12. Comparison between observed absorption and computed absorption.

and the absorption measurement by the riometer. The collision frequency profile is assumed to be of the log-linear type, that is, $\nu=\nu_{0} \exp (-h / H)$, where $h$ is the altitude from the ground level, $H$ is the scale height and $\nu_{0}$ is a constant (BUDDEN, 1961). The best-fitting curve is derived by the method of least squares. The collision frequency thus obtained is expressed as $\nu=1.49 \times 10^{9} \exp (-h / 16.3)$. In this equation, the scale height $H=16.3$ is large compared with the usual scale height of several $\mathrm{km}$; this is partly caused by the assumption of the simple log-linear collision frequency profile. Figure 12 shows a comparison between observed absorption and computed absorption by using the above derived collision frequency and the electron density measured with rockets. Figure 13 shows the collision frequency profile obtained. The collision frequency in the present experiments is lower than that of previous data at lower altitudes, lies at about the midpoint of the values in the middle altitude region, but has a lower value at high altitudes. Figure 14 shows the absorption coefficient profiles at $30 \mathrm{MHz}$, which are calculated by using the electron density profiles and the collision frequency profile. From this, it is clear that for all of the cases except S-210JA19 , there exists a maximum absorption layer in the region between $75 \mathrm{~km}$ and $85 \mathrm{~km}$, and the location of this altitude is not strongly dependent on the magnitude of the ionospheric disturbance. The region above $120 \mathrm{~km}$ scarcely contributes to the absorption.

The ionograms observed at Syowa Station, Antarctica show that an $E_{s}$ layer almost always exists in the nighttime (RADIo RESEARCH LABORATORIES, 19711972). Thus, the result obtained by the rocket S-210JA-19 may be assumed to be a typical example of the night $E_{s}$ layer profile from the consideration of the ionogram, riometer measurement and geomagnetic variation. There exists always an ionizing source of the night $E_{s}$ in the auroral zone. The energetic 
particles associated with auroral phenomena increase the electron density, and the increase in the electron density is superimposed on the night $E_{s}$ layer during the auroral disturbances.

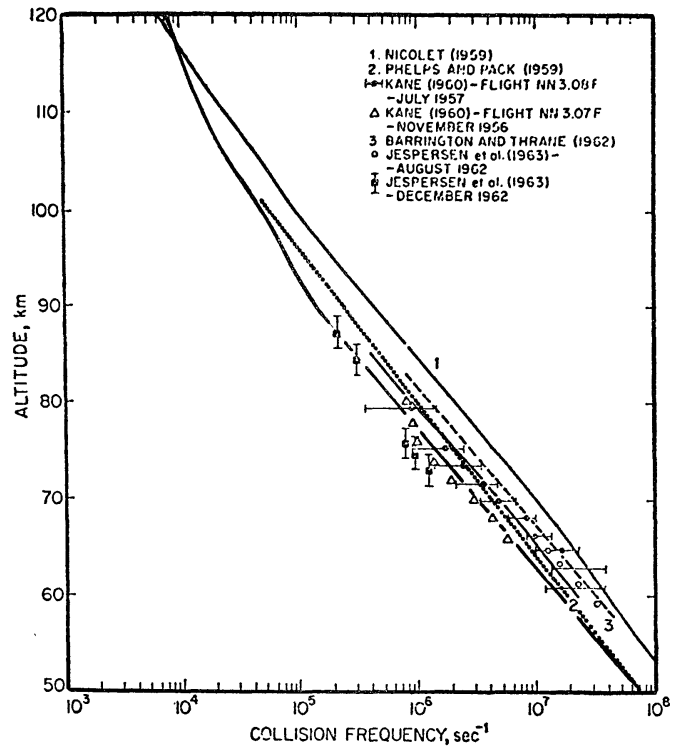

Fig. 13. Collision frequency profiles. The dotted line shows the collision frequency profile which is derived from the best fitting curve of the observational results of electron density measurements and cosmic noise absorption measurements by the method of least squares. Other profiles are after Whitten and Poppoff (1965); 1: the upper solid line, 2: the medium solid line, 3: the medium chain line, and the lower solid line are after HANSON (1961).

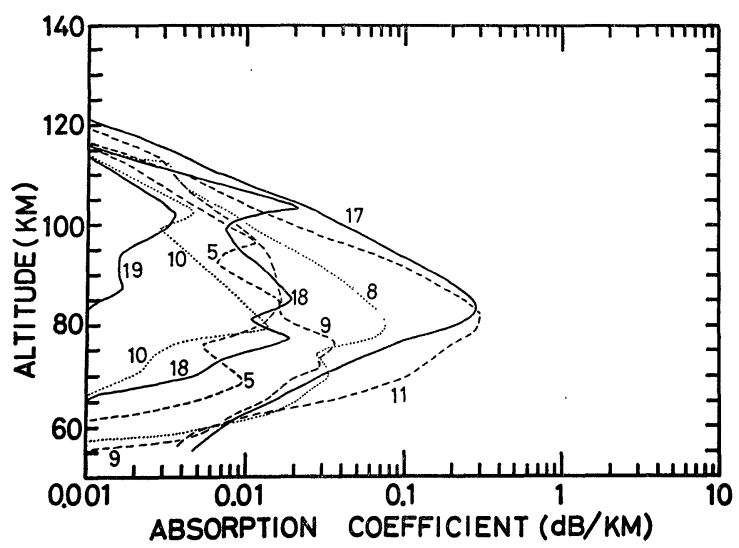

Fig. 14. Absorption coefficient profiles. 


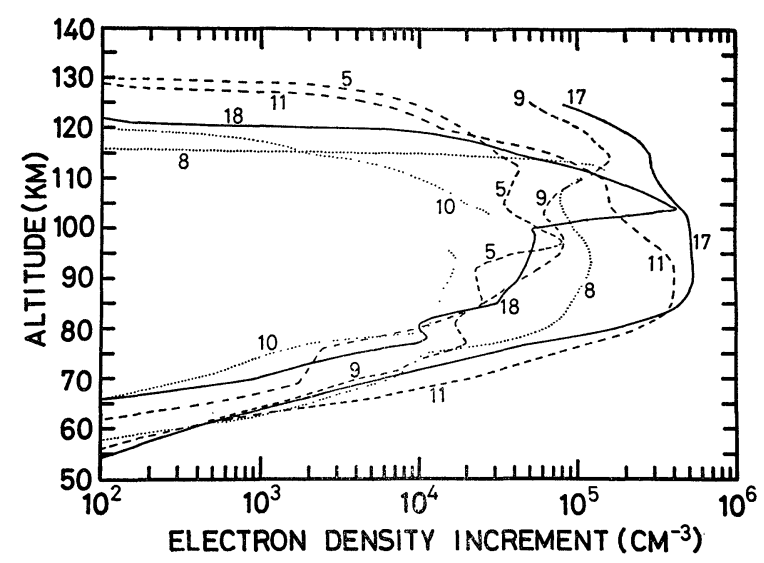

Fig. 15. Profiles of the increment of the electron density.

The increment of the electron density is discussed in the following. Figure 15 shows the profiles of the increments of the electron density which are the differences between the electron density observed by each rocket and the electron density obtained by S-210JA-19. From this graph it is clear that all the profiles of the increment of the electron density show nearly the same parabolictype shape and that the heights of the peak electron density are located in the region between $90 \mathrm{~km}$ and $100 \mathrm{~km}$. The curve of the electron density increment has double peaks in the cases of S-210JA-8 as well as in the case of S-210JA-18; however, the upper peak is associated with the visible aurora in analogy to the case of S-210JA-18 and is not related to CNA to any great extent. As regards the result by S-210JA-10, the approximation of the electron density around $100 \mathrm{~km}$ may not be a good one, so there appears a decrease in the electron density around $100 \mathrm{~km}$.

Figure 16 shows the relation between the maximum increment of the electron density and cosmic noise absorption. The empirical formula which is deduced from this figure is as follows:

$$
\Delta n_{e}=\exp (0.205 x+4.67)
$$

where $\Delta n_{e}$ is the maximum increment of the electron density per $\mathrm{cm}^{3}$ and $x$ is the cosmic noise absorption in $\mathrm{dB}$. The dotted lines to the extreme left of Fig. 16 are measurements for S-210JA-10. They deviate from the straight line; this is partly due to the comparatively small disturbance of the ionosphere.

Figure 17 shows the relation between the height of the peak electron density and cosmic noise absorption. The empirical formula is as follows:

$$
h_{m}=-2 x+100 \text {, }
$$

where $h_{m}$ is reckoned in $\mathrm{km}$. 


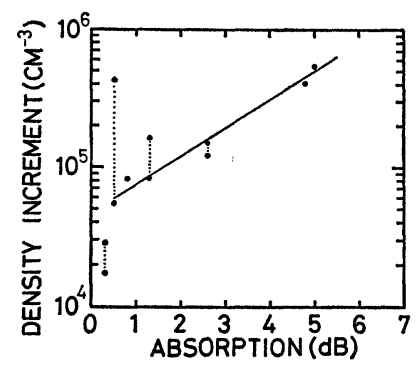

Fig. 16. Relation between the maximum electron density increment and cosmic noise absorption.

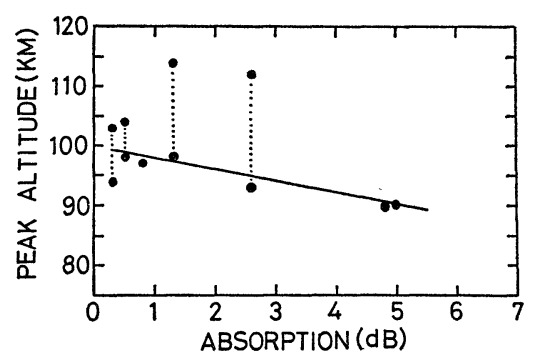

Fig. 17. Relation between the height of the peak of electron density increment and cosmic noise absorption.

\section{Concluding Remarks}

In the previous sections, electron density profiles below about $130 \mathrm{~km}$ during auroral disturbances, and discussion of the relation between electron density profiles and riometer observations are presented. The observed electron density distributions in the polar ionosphere strongly change according to the degree of the disturbance. The electron density profile has a close relation to auroral structures; therefore, there are cases in which the profiles in the ascending and descending modes are different from each other (see, for example, the cases of S-210JA-9 and -18).

The peak of the absorbing layer during polar cap absorption was estimated to be located in the range between $55 \mathrm{~km}$ and $60 \mathrm{~km}$ throughout the day at College, Alaska by PARThasarathy et al. (1963), but the absorbing layer at Syowa Station is located at somewhat higher altitudes, that is, around $85 \mathrm{~km}$. Though only the profiles in the nighttime are considered in this paper, the profiles in the daytime can be considered to be similar according to such observations, that is, the peak of the increment of the electron density from the quiet condition exists in the range between $90 \mathrm{~km}$ and $110 \mathrm{~km}$.

The detailed discussion of these observations, however, is a future problem.

As the polar ionosphere is very complicated, its interpretation requires other data such as the intensity and spectrum of auroral electrons, auroral $\mathrm{X}$ ray intensity and so on. Simultaneous measurement of such quantities by sounding rockets is also a future problem.

The author would like to thank all members of the wintering parties of the 12th, 13th and 14th JARE for their kind support and cooperation in launching the rockets at Syowa Station, Antarctica. The author's deep gratitude is also tendered to Prof. K. Hirao of the Institute of Space and Aeronautical Science, University of Tokyo and Dr. N. Wakai of the Radio Research Laboratories for their valuable discussions. The author is also grateful to Prof. T. Yonezawa 
of the Chubu Institute of Technology for his critical reading of the manuscript. This research was supported by the National Institute of Polar Research.

\section{REFERENCES}

American Geophysical Union, Special issue: Papers presented at COSPAR Symposium on $D$ and E-region ion chemistry, Radio Sci., 7, 1-213, 1972.

BANKS, P.M., C.L. RINO, and V.B. WICKWAR, Incoherent scatter radar observations of westward electric fields and plasma densities in the auroral ionosphere, I, J. Geophys. Res., 79, 187198, 1974.

Belrose, J.S. and M.J. Burke, Study of the lower ionosphere using partial reflection, 1. Experimental techniques and method of analysis, J. Geophys. Res., 69, 2799-2818, 1964.

Belrose, J.S., ed., Proc. of Conference on Ground-based Radio Wave Propagation Studies of the Lower Ionosphere, Defence Research Telecommunications Establishment, Ottawa, Canada, 1967.

Belrose, J.S., M.J. Burke, T.N.R. Coyne, and J.E. Reed, D-region measurements with the differential absorption, differential-phase partial-reflection experiments, J. Geophys. Res., 77, 4829-4838, 1972.

Budden, K.G., Radio Waves in the Ionosphere, Cambridge University Press, Cambridge, 1961.

Derblom, H. and L. Ladell, $D$-region parameters at high latitudes obtained from rocket experiments, J. Atmos. Terr. Phys., 35, 2123-2130, 1973.

EJIRI, M., T. Dote, S. Miyazaki, T. Aso, and S. Matsumura, Electron density measurements with R.F. and D.C. plasma probes in low density plasmas, Rept. Ionos. Space Res. Japan, 27, 229-232, 1973.

ElliNG, W., Average night-time electron density profiles between 87 and $115 \mathrm{~km}$ derived from absorption measurements at 10 fixed frequencies from 250 to $1000 \mathrm{kHz}$ at Tsumeb $\left(19^{\circ} \mathrm{S}\right), J$. Atmos. Terr. Phys., 36, 619-638, 1974.

Ferraro, A.J., H.S. Lee, J.N. Rowe, and A.P. Mitra, An experimental and theoretical study of the $D$-region -I. Mid-latitude $D$-region electron density profiles from the radio wave interaction experiment, J. Atmos. Terr. Phys., 36, 741-754, 1974.

Findlay, J.A. and L.H. BRACE, Cylindrical electrostatic probes employed on Alouette II and Explorer XXXI satellites, Proc. IEEE, 57, 1054-1056, 1969.

Hakura, Y., ed., Solar-terrestrial events in August 1972, Rept. Ionos. Space Res. Japan, 27, 145189, 1973.

Hanson, W.B., Structure of the ionosphere, in Satellite Environment Handbook, edited by F.S. Johnson, pp. 27-46, Stanford University Press, Stanford, California, 1961.

HAUG, A., Electron densities in the auroral zone $D$-layer during quiet ionospheric conditions, in Electron Density Profiles in Ionosphere and Exosphere, edited by J. Frihagen, pp. 61-65, NorthHolland Publishing Company, Amsterdam, 1966.

Hirasawa, T., T. Nagata, S. Kawaguchi, and K. Hirao, Rocket observations of electron density of daytime ionosphere at Syowa Station, Antarctica, Rept. Ionos. Space Res. Japan, 24, 237-243, 1970.

Holt, O., B. Landmark, and F. Lied, Observation of electron density in the $D$ region during polar radio blackout conditions, in Electron Density Profiles in the Ionosphere and Exosphere, edited by B. Maehlum, pp. 37-50, Pergamon Press, London, 1962.

Jespersen, M., O. Petersen, J. Rybner, B. Buelland, O. Holt, B. Landmark, and J.A. Kane, Electron and ion density observations in the $D$-region during auroral absorption, Planet. Space Sci., 12, 543-551, 1964.

Jespersen, M., A. HAUG, and B. LANDMARK, Electron density and collision frequency observa- 
tions in the arctic D-region, in Electron Density Profiles in Ionosphere and Exosphere, edited by J. Frihagen, pp. 27-30, North-Holland Publishing Company, Amsterdam, 1966.

Kamiyama, H., Ionization and excitation by precipitating electrons, Rept. Ionos. Space Res. Japan, 20, 171-187, 1966a.

KamiYama, H., Flux of bremsstrahlung photons caused by energetic electrons precipitating into the upper atmosphere, Rept. Ionos. Space Res. Japan, 20, 374-394, 1966b.

Kamiyama, H., The dependence of the relative intensities of some of the auroral line upon the energy spectrum of precipitating electrons, The Science Reports of the Tohoku University, 18, 83-90, 1967a.

Kamiyama, H., The electron density distribution in the lower ionosphere produced through impact ionization by precipitating electrons and through photoionization by the associated bremsstrahlung X-rays, J. Geomag. Geoelectr., 19, 27-47, $1967 \mathrm{~b}$.

Lerfald, G.M., C.G. Little, and R. Parthasarathy, $D$-region electron density profiles during auroras, J. Geophys. Res., 69, 2857-2861, 1964.

MAEDA, K., Mid-latitude electron density profile as revealed by rocket experiments, J. Geomag. Geoelectr., 21, 557-567, 1969.

MAedA, K., Study on electron density profile in the lower ionosphere, J. Geomag. Geoelectr., 23, 133-159, 1971.

Mechtly, E.A. and L.G. Sмith, Changes of lower ionosphere electron densities with solar zenith angle, Radio Sci., 5, 1407-1412, 1970.

Ogawa, T., H. Mori, and S. MiYazaki, Electron density irregularities observed in the antarctic auroral $E$ region, $J$. Radio Res. Labs., 22, 1975 (in press).

Parthasarathy, R., G.M. Lerfald, and C.G. Little, Derivation of electron-density profiles in the lower ionosphere using radio absorption measurements at multiple frequencies, $J$. Geophys. Res., 68, 3581-3588, 1963.

RADIO RESEARCH LABORATORIES, Ionospheric data at Syowa Station (Antarctica), ION. ANT.-16, $-17,-18,-19$, Jan. 1971-Dec. 1972.

Radio ReSEARCh LABORAtories, Solar-terrestrial disturbances of August 1972, Rev. Radio Res. Labs., 19, 245-390, 1973 (in Japanese).

ReEs, M.H., Ionization in the earth's atmosphere by aurorally associated bremsstrahlung X-rays, Planet. Space Sci., 12, 1093-1108, 1964.

Rees, M.H., A.I. Stewart, and J.C.G. WAlker, Secondary electrons in aurora, Planet. Space Sci., 17, 1997-2008, 1969.

RINNERT, K., Electron density profiles in the lower ionosphere deduced from long path VLF wave propagation, Radio Sci., 8, 829-836, 1973.

Rowe, J.N., A.P. Mitra, A.J. Ferraro, and H.S. Lee, An experimental and theoretical study of the $D$-region - II. A semi-empirical model for mid-latitude D-region, J. Atmos. Terr. Phys., 36, 755-785, 1974.

SeCHRIST, C.F., Interpretation of D-region electron densities, Radio Sci., 5, 663-671, 1970.

Shellman, C.H., Electron-density distributions in the lower ionosphere with associated error limits derived from VLF and LF sounder data, Radio Sci., 5, 1127-1135, 1970.

SMith, L.G., Rockt observations of sporadic $E$ and related features of the $E$ region, Radio Sci., 1, 178-186, 1966.

UNIVERSITY OF ILLINOIS, Direct aeronomic measurements in the lower ionosphere-an informal conference record, Aeronomy Report, No. 1, Univ. of Ill., 1963.

University of Illinois, Second conference on direct aeronomic measurements, Aeronomy Report, No. 10, Univ. of Ill., 1965.

UNIVERSITY OF IllinoIS, Meteorological and chemical factors in $D$-region aeronomy-record of the third aeronomy conference, Aeronomy Report, No. 32, Univ. of Ill., 1969. 
WAKaI, N., Study on the nighttime $E$ region and its effects on the radio wave propagation, $J$. Radio Res. Labs., 18, 245-348, 1971.

WATKins, B.J. and E.A. Essex, Total electron content measurements during visible auroras, $J$. Atmos. Terr. Phys., 35, 1009-1013, 1973.

WATts, J.M., The interpretation of nighttime low-frequency ionograms, J. Geophys. Res., 63, 717-726, 1958.

Webrer, W., The production of free electrons in the ionospheric $D$ layer by solar and galactic cosmic rays and the resultant absorption of radio waves, J. Geophys. Res., 67, 5091-5106, 1962.

Whitten, R.C. and I.G. PoppofF, Physics of the Lower Ionosphere, Prentice-Hall, Inc., Englewood Cliffs, N.J., U.S.A., 1965. 